\title{
Height and biomass of mangroves in Africa from ICEsat/GLAS and SRTM
}

\author{
TEMILOLA E. FATOYINBO*†, MARC SIMARD $\ddagger$ \\ †NASA Goddard Space Flight Center, 8800 Greenbelt Road, Mail Code 618, \\ Greenbelt, MD 20771,USA
}

‡ NASA Jet Propulsion Laboratory, 4800 Oak Grove Drive, MS 300-235E, Pasadena, CA, USA

\begin{abstract}
The accurate quantification of forest 3-D structure is of great importance for studies of the global carbon cycle and biodiversity. These studies are especially relevant in Africa, where deforestation rates are high and the lack of background data is great. Mangrove forests are ecologically significant and it is important to measure mangrove canopy heights and biomass. The objectives of this study are to estimate: 1 . The total area, 2. Canopy height distributions and 3. Aboveground biomass of mangrove forests in Africa. To derive mangrove 3-D structure and biomass maps, we used a combination of mangrove maps derived from Landsat ETM+, LiDAR canopy height estimates from ICEsat/GLAS (Ice, Cloud, and land Elevation Satellite/Geoscience Laser Altimeter System) and elevation data from SRTM (Shuttle Radar Topography Mission) for the African continent. More specifically, we extracted mangrove forest areas on the SRTM DEM using Landsat based landcover maps. The LiDAR (Light Detection and Ranging) measurements from the large footprint GLAS sensor were used to derive local estimates of canopy height and calibrate the Interferometric Synthetic Aperture Radar (InSAR) data from SRTM. We then applied allometric equations relating canopy height to biomass in order to estimate above ground biomass (AGB) from the canopy height product. The total mangrove area of Africa was estimated to be $25960 \mathrm{~km}^{2}$ with $83 \%$ accuracy. The largest mangrove areas and greatest total biomass was found in Nigeria covering $8573 \mathrm{~km}^{2}$ with $132 \times 10^{6} \mathrm{Mg}$ AGB. Canopy height across Africa was estimated with an overall root mean square error of $3.55 \mathrm{~m}$. This error also includes the impact of using sensors with different resolutions and geolocation error which make comparison between measurements sensitive to canopy heterogeneities. This study provides the first systematic estimates of mangrove area, height and biomass in Africa. Our results showed that the combination of ICEsat/GLAS and SRTM data is well suited for vegetation 3-D mapping on a continental scale.
\end{abstract}

\section{Introduction}

The measurement of forest biomass is crucial for carbon cycle and climate change studies. However, the amount and distribution of forest biomass is still poorly understood. Global estimates of terrestrial biomass range from $385 \times 10^{9} \mathrm{Mg}$, to $650 \mathrm{x}$ $10^{9} \mathrm{Mg}$ and forests alone hold about 70-90\% of the terrestrial biomass (Houghton et al. 2009). Mangrove forests only cover about $1 \%$ of the Earth's terrestrial surface, but they are amongst the highest carbon storing and exporting ecosystems globally (Dittmar et al. 2006, Donato et al. 2011).

Estimating distribution and biomass of mangrove forests is challenging due to the difficult physical environment of these forests. They are constantly inundated by diurnal 
tides and the characteristic aboveground roots often hinder in situ measurements. Largescale field measurements of mangroves are therefore rare to inexistent. The measurements that do exist are usually tailored towards a particular study, and the sampling and measurement methodologies vary. In Africa, studies of mangroves have focused on forest composition and zonation (Adams 2004; Dahdouh-Guebas 2004a; De Boer 2002; Ukpong 1995), management and utilization of mangrove products (Traynor and Hill 2008; Crona et al. 2009), the degradation of mangroves (Kruitwagen et al. 2008), and the ecology of mangrove-associated fauna (Faunce and Serafy, 2006). Recent assessments of mangrove cover in Africa mostly cover small areas, which makes the comparison with countrywide statistics difficult (Dahdouh-Guebas et al. 2004b). With the emergence of new remote sensing methodologies, it is now possible to systematically map mangrove spatial distribution and 3-D structure (Simard et al. 2006, 2008; Fatoyinbo et al. 2008; Lucas et al. 2007).

Optical Remote Sensing techniques have proven a reliable tool for the estimation of mangrove forest area globally, as shown by the large number of studies (Aschbacher et al. 1995; Smith et al. 1998; Dahdouh-Guebas et al. 2000; Kovacs et al. 2001; Satyanarayana et al. 2001; Dahdouh-Guebas et al. 2002; Sulong et al. 2002; Cohen and Lara, 2003; Gesche et al. 2004; Wang et al. 2003). The most comprehensive database of global mangrove cover is maintained by the UNEP World Conservation Monitoring Center, which published the World Mangrove Atlas (Spalding, 1997). This database is based on a review of the mangrove literature and mangrove cover estimated from multiple studies, datasets and methodologies.

For Africa in particular, the data, methodologies and timeframe used to generate the mangrove maps vary greatly, and a systematic methodology is needed to derive mangrove cover estimates. An updated version of global maps has recently been published (Giri et al. 2011). However, to obtain 3D structure and biomass, in addition to spatial distribution, active remote sensing from LiDAR and InSAR (Interferometric Synthetic Aperture Radar), are the best measurement tools available.

The only global InSAR and LiDAR datasets currently available are from the spaceborne SRTM (Shuttle Radar Topography Mission), and ICEsat/GLAS (Ice, Cloud and land Elevation Satellite/Geosciences Laser Altimetry System). The Shuttle Radar Topography Mission (SRTM), (Farr et al. 2007), was flown aboard the Space Shuttle Endeavor in February 2000 (Rodriguez, 2006). The SRTM measured terrain topography using dual antennae C-band Interferometric Synthetic Aperture Radar (InSAR), covering areas from $56^{\circ} \mathrm{S}^{\prime}$ and $60^{\circ} \mathrm{N}$ '. SRTM data is freely available at 1-arcsecond $(30 \mathrm{~m})$ resolution for the United States and 3-arcsecond $(90 \mathrm{~m})$, resolution globally. The SRTM DEM (Digital Elevation Model) is the most accurate, globally consistent elevation dataset covering $80 \%$ of the earth's landmasses. The SRTM height measurement is in fact biased by vegetation structure and can therefore be used to estimate canopy height (Kellndorfer et al. 2004). The GLAS instrument recorded full waveform altimetry using a $1064 \mathrm{~nm}$ laser that operated from 2003 to 2009. The LiDAR footprint has an approximate diameter of $70 \mathrm{~m}$, which is separated by $172 \mathrm{~m}$ along track (Schutz, 2005). In tropical regions, sampling is greatly hindered by consistent cloud cover. Although it was primarily a mission designed for the measurement of icesheet dynamics, it has been used to measure vegetation structure (Lefsky et al. 2005, 2007; Rosette et al. 2010). Previous work in the Santa Marta region of Colombia (Simard et al. 2008) has shown the possibility of using 
spaceborne InSAR (Interferometric SAR) and LiDAR data integration, to measure 3-D vegetation structure and biomass in mangroves.

The objectives of this study are to: 1) estimate mangrove heights on a continental scale from InSAR and LiDAR integration; 2) estimate the total AGB of mangrove forest in Africa and 3) estimate the associated errors in our measurements. In this study, we produce the first continental scale maps of mangrove spatial distribution, 3-D structure and above ground biomass (AGB), for Africa. We address new challenges introduced by large-scale mapping that are related to the variety of the biogeographical setting as well as the accuracy and sampling of data.

\section{MATERIALS AND METHODS}

\subsection{Study areas}

In continental Africa, mangroves grow in coastal areas ranging from Mauritania (19 $\left.\mathrm{N}^{\prime}\right)$, in the North West to Angola ( $\left.10^{\circ} \mathrm{S}^{\prime}\right)$, in the South West, and from South Africa ( $29^{\circ}$ $\left.\mathrm{S}^{\prime}\right)$, in the South East to Egypt ( $\left.28^{\circ} \mathrm{N}^{\prime}\right)$, in the North East, including Madagascar. On the Atlantic Coast of Western Africa there are a total of 7 indigenous species plus one introduced mangrove palm, Nypa fruticans, which are also found on the Atlantic and Pacific coasts of the Americas (Spalding et al. 1997). The indigenous species are: Acrostichum aureum, Avicennia germinans, Conocarpus erectus, Laguncularia racemosa, Rhizophora harrisonii, Rhizophora mangle and Rhizophora racemosa. The distribution limit of mangroves coincides with arid regions with rainfall below 30 $\mathrm{mm}$ /year (Saenger and Bellan, 1995).

On the Indian Ocean and Red Sea coastlines, the mangrove area is relatively small compared to the total length of the coastline, due to very arid conditions in areas North of the equator. There are fourteen species of mangrove present in this area, which differ from the west coast species. They are: Acrostichum aureum, Avicenna marina, Bruguiera cylindrical, Bruguiera gymnorrhiza, Ceriops tagal, Excoecaria agallocha, Heritiera littoralis, Lumnitzera racemosa, Pemphis acidula, Rhizophora mucronata, Rhizophora racemosa, Sonneratia alba, Sonneratia caseolaris and Xylocarpus granatum. The largest diversity on the continent is found in Mozambique, where ten of the species are present (Spalding et al. 1997).

\subsection{Mangrove extent from Landsat}

LANDSAT TM GeoCover data was acquired from the University of Maryland Global Land Cover Facility (http://glcf.umd.edu). The GeoCover dataset consists of Landsat data that has near global coverage and is available for three time periods ranging from 1973 to 2001. The Landsat ETM data used in this study had been orthorectified and georeferenced (Tucker et al. 2004).

A total of 117 Landsat ETM+ scenes from 1999 to 2002 were subset to include only low elevation coastal areas where mangroves may be present. All areas with elevations lower than $40 \mathrm{~m}$ were identified using the SRTM DEM. An unsupervised ISODATA classification was then applied to each Landsat image subset to discriminate mangroves from other types of vegetation (Green et al. 1998; Fatoyinbo et al. 2008). The classification was filtered using previously published maps, the World Mangrove Atlas 
141 (Spalding et al. 1997), visual inspection and high-resolution imagery from Google Earth 142 software. The resulting classes were manually combined into a final classification with 4

143 landcover types (mangrove, other vegetation, bare ground and water). In mangrove 144 forests in Central Africa, in particular Gabon and the Democratic Republic of Congo, no 145 cloudless Landsat scenes were available. In these areas with persistent cloud cover, we had to use cloud free Landsat data from 1989.

There are no local maps with known accuracy or sufficient field data available to assess relative accuracy. Therefore, we based our estimation of classification accuracy on an independent and systematic method for selecting validation points. We used points separated by $900 \mathrm{~m}$ (10 pixels), along a North-South running transect. The points were also spaced by 0.5 degrees longitude for the coast running from Senegal to Nigeria. For the remaining areas, we used points separated by $900 \mathrm{~m}$ along an East-West running transect, and spaced by 0.5 degrees latitude. We assessed mapping accuracy by visual interpretation of high-resolution images in Google Earth software. We only used points that were classified or identified as mangroves on the landcover map or in Google earth.

\subsection{Measurement of tree height from LiDAR-InSAR fusion}

ICESat/GLAS waveforms were acquired from the National Snow and Ice Data Center (NSIDC) website (http://nsidc.org/data/icesat). We used the GLA14 (Global land altimetry) data product to estimate canopy height. A total of 327 waveforms were used to estimate tree height in this study, as GLAS footprints were not available in all mangrove areas. GLAS data was available for sites in Senegal, Gambia, Guinea Bissau, Guinea, Nigeria, Cameroon, Gabon, Congo, Angola, Mozambique, Tanzania, Kenya, Eritrea and Madagascar.

The GLA14 product was produced by fitting up to six Gaussian distributions to the GLAS LiDAR waveform (Zwally et al. 2003). The shape and position of the Gaussians distributions describe the canopy vertical structure within the LiDAR footprint. It is generally assumed that the Gaussian peak furthest from the sensor is the ground return and the beginning of the waveform signal (i.e. first return with voltage above the noise level) is the return from the top of the canopy (Harding and Carabajal, 2005). The cumulative distribution (i.e. percentile) of the energy within the waveform is generally used to describe the vertical distribution of scatterers (e.g. leaves and branches) within the canopy. The percentile is computed from the beginning of the waveform (i.e. last return above the noise level). A relative height $\left(\mathrm{rh}_{\mathrm{x}}\right)$ is defined as the distance between the point where the percentile energy reaches $\mathrm{x}$ and the location of the ground peak defined as $\mathrm{rh}_{0}$ (Lefsky et al. 2005, Lefsky et al. 2007). Figure 1 shows an example of a waveform and the location of GLAS footprints used.

We only used data from cloud-free profiles and excluded all waveforms that did not have suitable data for determining tree heights. We excluded waveforms with a single Gaussian peak, which generally meant the footprint measured water or bare soil areas. We also excluded waveforms with low signal to noise ratio (i.e. below 50), which may have been reflected from clouds, or where Gaussians fits may include noise peaks. We found high signal to noise ratios up to 300 in the GLAS data.

SRTM version 4 data were downloaded from the Consultative Group for Agricultural Research (CGIAR). We used 30 SRTM scenes to build a single SRTM DEM covering 
the coast of Africa mosaic. Using the mangrove landcover map, we masked all nonmangrove areas on the SRTM DEM. This resulted in an uncalibrated height map of the mangrove areas. In forests, the C-band Radar signal penetrates into the canopy to scatter with all forest components and the ground. Thus, the radar height estimate (i.e. radar phase center) lies somewhere within the canopy volume, which can be used to estimate canopy height (Kellndorfer et al. 2004; Gillespie et al. 2006). Based on the reasonable assumption that mangroves are located at sea level, the elevation measured by SRTM (i.e phase center) is directly related to canopy height and can be calibrated to estimate the canopy height of mangrove forests (Simard et al. 2006).

The SRTM pixel corresponding to the GLAS shots were extracted (Figure 1). Assuming that represents the canopy height, we derived linear regressions between the GLAS point's rh $h_{75}$ values (relative height of the canopy at the $75^{\text {th }}$ percentile minus $r h_{0}$ ), and DEM height $\left(\mathrm{H}_{\text {SRTM }}\right)$ values to determine the regression equation of the form:

$$
\mathrm{rh}_{75}=\mathrm{a} * \mathrm{H}_{\mathrm{SRTM}}+\mathrm{b}
$$

Studies of forest biomass worldwide have shown that there is a strong correlation between tree size, in terms of diameter and height, and tree biomass. In general, the Diameter at Breast Height (DBH), of a tree is the strongest predictor of aboveground biomass (Chave et al. 2005). For mangrove forests, a global stand height-biomass allometric equation was calculated by Saenger and Snedaker (1993):

$$
\text { Biomass }\left(\mathrm{Mg} \mathrm{ha}^{-1}\right),=10.8 * \text { Height }(\mathrm{m})+35(2)
$$

This equation was obtained from 43 field datasets distributed globally $\left(r^{2}=0.59\right.$ and RMSE $=43.8$ ). To compute total aboveground biomass and aboveground biomass distribution of mangroves on the continental scale, we used $\mathrm{rh}_{75}$ and equation (2) to derive the biomass values as this equation was computed for a large range of tree heights and was derived to be applicable globally. [Insert figure 1 here]

\section{Results and Discussion}

All of the results were calculated and mapped on a per country basis to facilitate comparison with previously published results and data distribution. The maps are freely available for Google earth software at http://www-radar.jpl.nasa.gov/coastal.

\subsection{Mangrove landcover map}

The total area of mangrove cover in Africa was found to be $25960 \mathrm{~km}^{2}$ with $83 \%$ accuracy. The five largest mangrove areas were - in decreasing order - in: 1) Nigeria, 2) Mozambique, 3) Guinea Bissau, 4) Madagascar and 5) Guinea. The smallest area of mangroves is found in Mauritania at $0.4 \mathrm{~km}^{2}$. With $8573 \mathrm{~km}^{2}$, Nigeria has the fourth largest mangrove area in the world, after Indonesia, Brazil and Australia. The overall accuracy of the land cover map was of $83 \%$ considering $10 \%$ omissions and $7 \%$ commissions, based on a total of 540 points (Table 1). The main sources of error in the landcover map were due to difficulties distinguishing between mangrove forests and 
other forest types, such as coastal forests or rainforests and the presence of clouds, especially in the equatorial regions. In Central Africa the map accuracy was much lower, at $68 \%$, due to the high cloud cover. The landcover maps for Nigeria, Cameroon, Tanzania and Kenya are presented in figure 2 and the breakdown of mangrove area by state is presented in table 2. [Insert table 1]

Although it is not our objective to assess changes in the spatial extent of mangroves over time, it is important to compare our results with previous studies. Overall, the landcover maps show that the mangrove area of Africa is smaller than the previously estimated $30000 \mathrm{~km}^{2}$ (Spalding et al. 1997, FAO 2007). However the exact estimate of mangrove area change due to natural and anthropogenic disturbances cannot be calculated because of the differences in data collection methodologies, the variations in the definition of mangrove forests and the differences in resolution of the datasets used in the previous estimates. The large decreases in mangrove area estimates are in part due to degradation in mangrove area but also due to different definitions of "mangrove areas".

In many studies, mangrove area was overestimated because it was difficult to differentiate between mangrove forests and adjacent mudflats, salt marshes, swamp forests and bare areas using low-resolution data $(1 \mathrm{~km} \mathrm{x} 1 \mathrm{~km})$. The consistent cloud cover in many tropical areas and poor coverage of optical data. This is the case in many of the tropical regions, with extreme discrepancies in Congo and Côte d'Ivoire for example. Furthermore, certain studies include the "mangrove palm" Nypa fruticans as a mangrove species, whereas other studies do not. In this study we did not include bare ground and mudflats and also did not count uniform Nypa stands as mangrove areas as much as was possible. Other very large differences in area measurement such as in Egypt, Côte d'Ivoire, Sudan, are probably due to a lack of up-to-date studies and remotely sensed data leading to poor mapping capabilities at the time of the study.

A direct comparison or estimation of the amount and rate of decrease or degradation in mangrove area throughout Africa is difficult, but we know that mangrove areas have decreased on the continent due to anthropogenic influences. Over $60 \%$ of Nigeria's mangrove stands are found in the Niger Delta region, yet studies in the Niger Delta have shown that mangroves have greatly suffered from the development and rapid increase in oil and gas exploitation in the area and the resulting pollution by oil spills, rapid urbanization and dredging of canals, as well as the introduction of the invasive mangrove palm Nypa fruticans (James, G. K. et al. 2007). In general, decreases in mangrove area in West Africa are primarily attributed to anthropogenic pressures in coastal regions leading to conversion of land use for the production of salt and rice, urban and tourism development, pollution, lack of sustainable resource management and recently, the development of shrimp aquaculture (FAO, 2007). In eastern Africa, large decreases in mangrove areas are primarily due to felling for household products and conversion to urban, agricultural and touristic areas and diversion of freshwater from damming. These measurement inconsistencies justify the need for a systematic approach to mangrove mapping as presented in this study.

\subsection{Height and biomass measurements}




\subsection{Error Analysis}

The RMSE (Root Mean Square Error) is of $3.55 \mathrm{~m}$. Calibrated canopy height maps for West and East Africa are presented in Figure 3. In previous studies comparing SRTM derived canopy height with field and airborne LiDAR data, resulted in RMS errors of 1.6 $\mathrm{m}$ and $2.0 \mathrm{~m}$ respectively (Fatoyinbo et al. 2008; Simard et al. 2006). Our results are very similar to these studies. These are the lowest errors that can be achieved using data fusion of these LiDAR and radar sensors without the incorporation of field validation. [insert figure 2]

Based on our results, the equatorial areas of Africa are the best suited for the growth of tall mangroves but not for their expansion, since the actual mangrove area is small in these countries. Average biomasses per country ranged from $76 \mathrm{Mg} \mathrm{ha}^{-1}$ in the Republic of Benin to $178 \mathrm{Mg} \mathrm{ha}^{-1}$ in Congo. The greatest total biomass values were found in Nigeria and Guinea Bissau, the lowest in Mauritania.

Previous studies of mangrove canopy height, biomass and distribution have shown that geographical setting is more important in determining mangrove structure and distribution than the latitudinal distribution (Fatoyinbo et al. 2008). This is particularly evident on the African continent, and particularly in West Africa, where a great proportion of mangroves grow within a small range of latitudes, but the forest area and structure vary greatly. In Nigeria mangroves are extensive and canopy height can be very tall, but in adjacent Benin and Togo, their distribution is very limited and canopy height is short. In Senegal, Gambia, Guinea Bissau and Guinea, mangroves extend very far inland, up to $160 \mathrm{~km}$ in Gambia, but at the same latitudes in East Africa, in Somalia, Djibouti and Eritrea, mangrove forests are sparse. Estuaries and deltas with extensive freshwater supply are the most advantageous for mangrove growth, both in terms of height and extent, and have a much greater influence than latitude. Indeed, all of the mangrove forests with large areas, tall trees and/or high biomass grow either in estuaries or in deltas. [Insert figure 3 and table 2]

The fact that we used 3 different data sets in this study also increases the incidence of error in our calculations. In the landcover classification, we observed $83 \%$ accuracy, with $17 \%$ errors from commissions and omissions from the classification. The systematic error (i.e. bias) from the calibration equation was low at $1 \%$.

Cloud cover was a major source of error, especially in central African nations, where cloud cover is persistent. Some systematic but localized errors in the SRTM DEM resulted in overestimation of tree height and biomass, but also in the omission of mangrove areas. For example on an island in the Niger Delta, the DEM indicated that canopy height was $363 \mathrm{~m}$. This is a common error with the SRTM DEM on islands that may have been caused by difficult SRTM interferometric phase unwrapping (i.e. the method to retrieve elevation from radar interferometric phase). Because this measurement 
was too high for mangroves this area was omitted from the height and biomass estimation.

The geolocation error of the GLAS instrument ranges from $4.6 \mathrm{~m}$ to $53.4 \mathrm{~m}$ (according to NSIDC), which greatly influences the accuracy of the height measurement, particularly if the canopy is heterogeneous. The actual height derived from the GLAS waveform may therefore not correspond to the mean canopy height of the SRTM pixel that is measured. The height estimated from the LiDAR waveform is affected by forest composition and heterogeneity as canopy shape, reflective properties and the associated photon interactions all influence the structure of the waveform (Rosette et al. 2010, North et al. 2010). In addition, the waveform is most sensitive to the footprint center since laser gain decreases with distance from the center of the footprint. Mangrove forests are characterized by distinct "zones" that are dependent on the location relative to the coast or river and that show great heterogeneity in forest structure, type and composition (Tomlinson, 1994). When the GLAS footprint is close to the border of two zones, this can result in large discrepancies in height measurement (Figure 4). Although low in species composition, mangrove forests are very heterogeneous, ranging from tall, dense forests to very short, sparse and shrubby areas within a few hundred meters. The 70 m GLAS footprint is not always able to characterize this heterogeneity, resulting in discrepancies with SRTM measurements. For example when looking at the variance within a seemingly homogeneous forest in Cameroon, we found that within a single $1 \mathrm{~km}^{2}$ patch, the canopy height standard deviation was $5 \mathrm{~m}$, showing that the height within a forest can vary greatly within a small area (Figure 4). Therefore, since the trees measured by SRTM and GLAS are not exactly the same, the differences between the height measurements and what we state as the error of the measurement are inflated. The differences in physical parameters measured by radar and LiDAR, in addition to differences in resolution also increase the height and biomass estimation error. These combinations of sources of error are illustrated in figure 5. [Insert figure 4]

The identification of the ground location within the waveform influences the estimate of the canopy height and therefore also of the biomass. In tidal forests, such as mangroves, the height of the ground, or of the water level may vary depending on the tidal level. This may influence the GLAS ground and therefore the relative height estimates. On the other hand, microtopographic features will most likely average out by selecting the furthest Gaussian peak as the ground. In this study we chose to use $\mathrm{rh}_{75}$ as the height of the canopy as this measurement resulted in the lowest error when comparing to the SRTM measurement.

The RMS error of equation (3) is of $65.4 \mathrm{Mg} \mathrm{ha}^{-1}$. This error is high due to large variability in the measurements taken and the natural variability of the data set. Since this is a global equation, it does not take into account local variability in height and biomass. There is generally a great amount of uncertainty when working with height-biomass allometric equations. Because height is not the most direct indicator of tree biomass (Chave et al. 2005), some error is always introduced into the estimate when deriving biomass from height. To obtain more accurate measurements of biomass from radar and LiDAR data, it is crucial that more reliable allometric equations be developed as a function of vertical structure parameters. [Insert figure 5]

367

368

\section{Conclusions}


Mangroves are one of the most important ecosystems in coastal areas in terms of ecology and economy, but they are still being destroyed and degraded at great rates. The lack of field studies and homogeneous historical data has made the calculation of rates of change in mangrove cover difficult. In this paper, we produced the first systematic estimate of mangrove cover, structure and biomass for the entire African continent and Madagascar. This map can now be used as a baseline as the techniques used in this paper allows the recalculation and reproduction with updated estimates of canopy height and allometry in Africa as well as comparison with the rest of the world.

The total area of mangrove forest in Africa for the period of 1999 to 2000 based on the classification of Landsat ETM+ images is of $25960 \mathrm{~km}^{2}$ with the largest area found in Nigeria at $8573 \mathrm{~km}^{2}$ and the smallest area in Mauritania with $0.4 \mathrm{~km}^{2}$. The overall accuracy of the map was of $83 \%$ considering $10 \%$ omissions and $7 \%$ commissions. This overall estimate is lower than previous estimates of mangrove cover in the World Mangrove Atlas (Spalding, 1997), mostly due to classification errors from high cloud cover and difficulties in distinguishing between mangroves and adjacent forests. We do believe that there is an overall decrease in mangrove cover that can be attributed to deforestation and degradation of mangroves from anthropogenic pressures, however, we cannot accurately quantify the rate and percent decrease in area because of the differences in methodology and datasets used between the various published estimates.

Since mangroves are a relatively homogeneous ecosystem that grows on flat terrain at sea level, the results from this study are some of the most accurate we can expect from a Radar/LiDAR integration study. The height maps derived from SRTM and GLAS data confirmed this type of data fusion to measure mangrove canopy height to be appropriate, with an average RMSE of $3.55 \mathrm{~m}$. This value includes the impact of canopy heterogeneity on the remote sensing measurement that is not geolocated. Previous studies using SRTM and LiDAR datasets in Colombia measured canopy height with an accuracy of $2.7 \mathrm{~m}$ (Simard et al. 2008). When similar methods using LiDAR were combined with field data, the RMSE decreased to $1.6 \mathrm{~m}$ in Mozambique (Fatoyinbo et al. 2008). To achieve even higher accuracy, or lower error, field validation of mangrove height and biomass calibration should therefore be included in future studies.

Overall, only 327 usable GLAS footprints were found for all mangrove areas in Africa. This is a very small sample size covering only $0.02 \%$ of the total mangrove area. This is however, the greatest number of systematic height measurements available. GLAS was not optimized for vegetation measurement, but as the only spaceborne LiDAR it is the only dataset available for continental-scale studies. We look forward to the future LiDAR and InSAR missions, which will provide greater coverage over forested areas.

\section{Acknowledgements}

414

Dr. Fatoyinbo would like to thank the NASA Postdoctoral Program for funding this research. The work presented in this paper was conducted at the Jet Propulsion Laboratory, California Institute of Technology, under contract with the National Aeronautics and Space Administration NASA, and at the NASA Goddard Space Flight Center. 


\section{References}

ADAMS, J.B., COLLOTY, B.M. and BATE, G.C., 2004, The distribution and state of mangroves along the coast of Transkei, Eastern Cape Province, South Africa. Wetlands Ecology and Management, 12, pp. 531-541.

ASCHBACHER, J., OFREN, R., DELSOL, J.-P., SUSELO,T.B., VIBULSRESTH,S. and CHARUPPAT, T., 1995, An integrated comparative approach to mangrove vegetation mapping using advanced remote sensing and GIS technologies: preliminary results. Hydrobiologica, 295, pp. 285-294.

CHAVE, J., ANDALO, C., BROWN, S., CAIRNS, M.A., CHAMBERS, J.Q., EAMUS, D., FÖLSTER, H., FROMARD, F., HIGUCHI, N., KIRA, T., LESCURE, J.P., NELSON, B.W., OGAWA, H., PUIG, H., RIERA, B. and YAMAKURA, T., 2005. Tree allometry and improved estimation of carbon stocks and balance in tropical forests. Oecologia, 145, pp. 87-99.

CRONA, B. I., RÖNNBÄCK, P., JIDDAWI, N., OCHIEWO, J., MAGHIMBI, S. and BANDEIRA, S., 2009, Murky water: Analyzing risk perception and stakeholder vulnerability related to sewage impacts in mangroves of East Africa. Global Environmental Change, 19, pp. 227 - 239.

DAHDOUH-GUEBAS, F. DE BONDT, R. ABEYSINGHE, P. D. KAIRO, J. G. CANNICCI, S. TRIEST and L. KOEDAM, N., 2004a, Comparative study of the disjunct zonation pattern of the grey mangrove Avicennia marina Forsk. Vierh. in Gazi Bay Kenya. Bulletin of Marine Science., 74, pp. 237-252.

DAHDOUH-GUEBAS, F., VAN POTTELBERGH, I., KAIRO, J.G., CANNICCI, S. and KOEDAM, N., 2004b, Human-impacted mangroves in Gazi Kenya: predicting future vegetation based on retrospective remote sensing, social surveys, and tree distribution. Marine Ecology-Progress Series, 272, pp. 77-92.

DAHDOUH-GUEBAS, F., VERHEYDEN, A., DE GENST, W., HETTIARACHCHI, S., and KOEDAM, N., 2000, Four decade vegetation dynamics in Sri Lankan mangroves as detected from sequential aerial photography: a case study in Galle. Bulletin of Marine Science, 672, pp. 741-759.

DAHDOUH-GUEBAS, F., ZETTERSTRÖM, T., RÖNNBACK, P., TROELL, M., WICKRAMASINGHE, A. and KOEDAM, N. 2002, Recent changes in land-use in the Pambala-Chilaw lagoon complex Sri Lanka, investigated using remote sensing and GIS: conservation of mangroves vs. development of shrimp farming. Environment, Development and Sustainability, 42, pp. 185-200.

DE BOER, W.F., 2002, The rise and fall of the mangrove forests in Maputo Bay, Mozambique. Wetlands Ecology and Management, 10, pp. 313-322. 
DITTMAR, T., HERTKORN, N., KATTNER, G. and LARA, R.J., 2006, Mangroves, a major source of dissolved organic carbon to the oceans. Global Biogeochemical Cycles, 20, pp. 1-7. M., and KANNINEN, M., 2011, Mangroves among the most carbon-rich tropical forests

and key in land- use carbon emissions. Nature Geoscience, 4, pp. 293-297.

FARR, T. G., ROSEN, P.A., CARO, E., CRIPPEN, R. T., DUREN, R., HENSLEY, S., KOBRICK, M., PALLER, M., RODRIGUEZ, E., ROTH, L., SEAL, D., SHAFFER, S., SHIMADA, J., UMLAND, J., WERNER, M., OSKIN, M., BURBANK, D., and ALSDORF, D., 2007, The Shuttle Radar Topography Mission. Review of Geophysics, 45, pp. 1- 33.

FATOYINBO, T. E., SIMARD, M. WASHINGTON-ALLEN, R. A. and SHUGART, H. H., 2008, Landscape-scale extent, height, biomass, and carbon estimation of Mozambique's mangrove forests with Landsat ETM+ and Shuttle Radar Topography Mission elevation data. Journal of Geophysical Research, 113, pp. 1-13.

FAUNCE, C.H. and SERAFY, J.E., 2006, Mangroves as Fish habitat: 50 years of field studies. Marine Ecology Progress Series, 318, pp. 1-18.

FAO FOOD and AGRICULTURE ORGANIZATION of the UNITED NATIONS, 2007, Mangroves of Africa 1980-2005: Country Reports, Forest Resources Assessment Working Paper No 135. Rome, FAO.

GESCHE, K., B. MICHAEL, W. STEFAN, and B. GERALD, 2004, Mapping land cover and mangrove structures with remote sensing techniques: A contribution to asynoptic GIS in support of coastal management in north Brazil. Environmental Management, 34, pp. 429-440.

GILLESPIE, T.W., ZUTTA, B.R., EARLY, M.K., and SAATCHI, S., 2006, Predicting and quantifying the structure of tropical dry forests in south Florida and the neotropics using spaceborne imagery. Global Ecology and Biogeography, 153, pp. 225-236.

GIRI, C. and MUHLHAUSEN, J., 2008, Mangrove Forest Distributions and Dynamics in Madagascar 1975-2005. Sensors, 8, pp. 2104-2117.

GIRI, C., OCHIENG, E., TIESZEN, L. L., ZHU, Z., SINGH, A., LOVELAND, T., MASEK, J. and DUKE, N., 2011, Status and distribution of mangrove forests of the world using earth observation satellite data. Global Ecology and Biogeography, 20, pp. 154-159.

GREEN, E.P, CLARK, C.D., MUMBY, P.J., EDWARDS, A.J. and ELLIS, A.C., 1998, Remote sensing techniques for mangrove mapping. International Journal of Remote Sensing, 19, pp. 935-956. 
HARDING, D. and CARABAJAL, C., 2005, ICESat waveform measurements of withinfootprint topographic relief and vegetation vertical structure. Geophysical Research

510 Letters, 32, pp. 1-4.

511

512

513

514

515

516

517

518

519

520

521

522

523

524

525

526

527

528

529

530

531

532

533

534

535

536

537

538

539

540

541

542

543

544

545

546

547

548

549

550

551

552

553

HOUGHTON, R.A., HALL, F.G., and GOETZ, S. J., 2009, Importance of biomass in the global carbon cycle. Journal of Geophysical Research, 114, pp. 1-13

JAMES, G.K., ADEGOKE, J.O., EKECHUKWU, S., NWILO, P. and AKINYEDE, J., 2007, Satellite-Based Assessment of the Extent and Changes in the Mangrove Ecosystem of the Niger Delta. Marine Geodesy, 30, pp 249-267.

KRUITWAGEN, G., PRATAP, H., COVACI, A. AND BONGA, S. W., 2008, Status of pollution in mangrove ecosystems along the coast of Tanzania. Marine Pollution Bulletin, 56, pp. 1022-1031.

KELLNDORFER, J., WALKER, W., PIERCE, L., DOBSON, C., FITES, J.A., HUNSAKER, C., VONA, J., and CLUTTER, M., 2004,Vegetation height estimation from Shuttle Radar Topography Mission and National Elevation Datasets. Remote Sensing of Environment, 933, pp. 339-358.

LEFSKY, M., HARDING, D., KELLER, M., COHEN, W., CARABAJAL, C., DEL BOM ESPIRITO-SANTO, F., HUNTER, M., DE OLIVEIRA JR., R. and DE CAMARGO, P., 2005, Estimates of forest canopy height and aboveground biomass using ICESat. Geophysical Research Letters, 32, pp. 1-4.

LEFSKY, M.A., KELLER, M., PANG, Y., DE CAMARGO, P. and HUNTER, M.O., 2007, Revised method for forest canopy height estimation from the Geoscience Laser Altimeter System waveforms. Journal of Applied Remote Sensing, 1, pp. 1-18.

LUCAS, R. M., MITCHELL, A. L., ROSENQVIST, A., PROISY, C., MELIUS, A. and TICEHURST, C., 2007, The potential of L-band SAR for quantifying mangrove characteristics and change: case studies from the tropics. Aquatic Conservation: Marine and Freshwater Ecosystems, 173, pp. 245-264.

NORTH, P.R.J., ROSETTE, J.A.B., SUÁREZ, J.C. and LOS, S.O., 2010, A Monte Carlo radiative transfer model of satellite waveform LiDAR. International Journal of Remote Sensing, 31, pp. 1343-1358.

RODRIGUEZ, E., MORRIS, E. and BELZ, J.E., 2006, A global assessment of the SRTM performance. Photogrammetric Engineering \& Remote Sensing, 723, pp. 249-260.

ROSETTE, J.A.B., NORTH, P.R.J., SUAREZ, J.C., LOS, S.O., 2010, Uncertainty within satellite LiDAR estimations of vegetation and topography. International Journal of Remote Sensing, 31, pp. 1325-1342.

SATYANARAYANA, B., MOHAMAD, K.A., IDRIS, I.F., HUSAIN, M.-L., and 
554 DAHDOUH-GUEBAS, F., 2011, Assessment of mangrove vegetation based on remote 555 sensing and ground-truth measurements at Tumpat, Kelantan Delta, East Coast of 556 Peninsular Malaysia. International Journal of Remote Sensing, 32, pp. 1635-1650

SAENGER, P. and BELLAN, M.F., 1995. The Mangrove vegetation of the Atlantic coast of Africa. (Toulouse: Université de Toulouse Press).

SAENGER, P. and SNEDAKER. S.C., 1993, Pantropical trends in mangrove aboveground biomass and annual litterfall. Oecologia, 96, pp. 293-299.

SCHUTZ, B. E., ZWALLY, H. J., SHUMAN, C. A., HANCOCK, D. and DIMARZIO, J. P., 2005, Overview of the ICESat Mission. Geophysical Research Letters, 32, pp. L21S01.

SIMARD, M., ZHANG, K.Q., RIVERA-MONROY, V.H., ROSS, M.S., RUIZ, P.L., CASTANEDA-MOYA, E., TWILLEY, R.R. and RODRIGUEZ, E., 2006, Mapping Height and Biomass of Mangrove Forests in Everglades National Park with SRTM Elevation Data. Photogrammetric Engineering and Remote Sensing, 723, pp. 299-311.

SIMARD, M., RIVERA-MONROY, V.H., MANCERA-PINEDA, J.E., CASTANEDAMOYA, E. AND TWILLEY, R.R., 2008, A systematic method for 3D mapping of mangrove forests based on Shuttle Radar Topography Mission elevation data, ICESat/GLAS waveforms and field data: application to Cienaga Grande De Santa Marta, Colombia. Remote Sensing of the Environment, 112, pp. 2131-2144.

SMITH, G. M., T. SPENCER, A. L. MURRAY, and J. R. FRENCH, 1998, Assessing seasonal vegetation change in coastal wetlands with airborne remote sensing: an outline methodology. Mangroves and Salt Marshes, 2, pp. 15-28.

SPALDING, M.D., BLASCO, F. and FIELD, C.D. (Eds.), 1997, World Mangrove Atlas. (Okinawa, Japan: The International Society for Mangrove Ecosystems).

TOMLINSON, P.B., 1994, The botany of mangroves. (Cambridge: Cambridge University Press)

TRAYNOR, C. H. and HILL, T., 2008, Mangrove utilisation and implications for participatory forest management, South Africa. Conservation and Society, 62, pp. 109116.

TUCKER, C.J., GRANT, D. M. and DYKSTRA, J. D., 2004, NASA's global orthorectified landsat data set. Photogrammetric Engineering and Remote Sensing, 703, pp. 313-322.

UKPONG, I.E., 1995, An ordination study of and leaf size differences in two red mangrove swamp communities in West Africa. Vegetatio, 116, pp. 147-159. 
600 WANG, Y., GREGORY, B., JARUNEE, MICHAEL, T., AMANI, N., JAMES, T., 601 LYNNE, H., ROBERT, B., and VEDAST, M., 2003, Remote sensing of mangrove 602 change along the Tanzania coast. Marine Geodesy, 26, pp. 35-48.

603

604 ZWALLY, H.J., SCHUTZ, R., BENTLEY, C., BUFTON, J., HERRING, T., MINSTER, 605 J., SPINHIRNE, J. and THOMAS, R., 2003, GLAS/ICESat L2 Global Land Surface 606 Altimetry Data V018, 15 October to 18 November 2003. Boulder, CO: National Snow 607 and Ice Data Center. Digital media. 